\title{
Journal of Economics and Business
}

Aseanomics

Journal homepage http://academicjournal.yarsi.ac.id/jeba

\section{Role Of Trusting Beliefs In Predicting Online Purchase Intentions}

\author{
Edi Komara ${ }^{1}$ \\ ${ }^{1}$ Program Studi Manajemen STIE Indonesia Banking School, Jakarta
}

\section{Article \\ Information \\ History of article: \\ Received: 22-11-2020 \\ Accepted: 22-12-2020 \\ Keywords: \\ Price Fairness, Firm's \\ Reputation, Uncertainty \\ Avoidance, Trusting Beliefs, \\ Purchase Intention.}

JEL Classification: M30

\begin{abstract}
Consumer behavior in every country, especially developing countries, must be different from consumer behavior in developed countries. This is a challenge faced by online shopping platforms to enter the Indonesian market by developing a new culture in terms of online shopping, as well as fostering trust in consumers in the products offered in order to attract consumer purchases. The success of a company in this case is e-commerce, namely the trust that is felt so that consumers have an interest in buying. Five marketplaces, namely Shopie, Bukalapak, Tokopedia, Lazada, and Blibi.com as providers of online product sales vendors from abroad must build trust that can be trusted for consumers, especially millennial consumers, in making transactions through online which causes consumer purchase interest, especially millennial consumers. Who are close to the development of the internet and receive new information in conducting online transactions. The design of this study uses an explanative analysis method by taking samples and questionnaires as the main tools, with the criteria of millennial consumer respondents, knowing products sold from abroad, and never product transactions from abroad. The data collected in this study were 110 respondents. By using the analysis technique of Structural Equation Modeling (SEM). The results showed that Uncertainty Avoidance had a negative and insignificant effect on Trusting Beliefs; Price Fairness had a positive and significant effect on Trusting Beliefs. Firm's Reputation has a positive and significant effect on Trusting Beliefs, and Trusting Beliefs has a positive and significant effect on Purchase Intention.
\end{abstract}

Kata Kunci:

Keadilan Harga, Reputasi

Perusahaan, Penghindaran

Ketidakpastian,

Kepercayaan

Kepercayaan, Niat

Membeli.

JEL Classification: M30

\begin{abstract}
Abstrak
Perilaku konsumen disetiap negara khususnya negara berkembang pasti berbeda dibandingkan perilaku konsumen di negara maju. Ini merupakan sebuah tantangan yang dihadapi oleh platform belanja online untuk masuk ke pasar Indonesia dengan mengembangkan budaya baru dalam hal berbelanja online, serta menumbuhkan kepercayaan kepada konsumen terhadap produk yang ditawarkan agar bisa menarik niat pembelian pada konsumen. Kesuksesan suatu perusahaan dalam hal ini merupakan e-commerce yaitu kepercayaan yang dirasakan agar para konsumen memiliki niat beli. Lima marketplace yaitu Shopie, Bukalapak, Tokopedia, Lazada, dan Blibi.com sebagai penyedia vendor penjualan online produk dari luar negeri harus membangun kepercayaan yang dapat dipercaya bagi konsumen khususnya konsumen millennial dalam melakukan transaksi melalui online yang menyebabkan niat pembelian konsumen, khususnya pada konsumen millennial yang dekat dengan perkembangan internet dan menerima informasi baru dalam melakukan transaksi online. Desain Penelitian ini menggunakan metode analisis eksplanatif dengan mengambil sampel dan kuesione sebagai alat utama, dengan kriteria Responden konsumen millennial, mengetahui produk yang di jual dari luar negeri, dan tidak pernah transaksi produk dari luar negeri. Data terhimpun dalam penelitian ini sebanyak 110 responden. Dengan menggunakan teknik analisis Structural Equation Modeling (SEM). Hasil penelitian menunjukkan bahwa Uncertainty Avoidance berpengaruh negatif dan tidak signifikan terhadap Trusting Beliefs, Price Fairness berpengaruh positif dan signifikan terhadap Trusting Beliefs. Firm's
\end{abstract}


Reputation berpengaruh positif dan signifikan terhadap Trusting Beliefs, dan

Trusting Beliefs berpengaruh positif dan signifikan terhadap Purchase Intention.

\footnotetext{
Edi Komala

Indonesian Banking School, Jl. Kemang Raya, Mampang, South Jakarta
}

edi.komara@ibs.ac.id

\section{PENDAHULUAN}

Mengutip data dari Global Web Index, Indonesia merupakan negara dengan tingkat adopsi ecommerce tertinggi di dunia pada 2019. Sebanyak 90 persen dari pengguna internet berusia 16 hingga 64 tahun di Indonesia pernah melakukan pembelian produk dan jasa secara online. Kegemaran masyarakat dalam berbelanja online rupanya semakin meningkat. Bank Indonesia (BI) mengestimasi jumlah nilai transaksi di 14 e-commerce terbesar Indonesia mencapai Rp 265,07 triliun di sepanjang tahun 2019. Jumlah nilai transaksi ini meningkat pesat dari nilai transaksi keseluruhan tahun 2017 yang sebesar Rp 80,82 triliun dan keseluruhan nilai transaksi sepanjang tahun 2018 yang mencapai Rp 145,95 triliun. Tren tersebut terjadi akibat mudahnya konsumen Indonesia untuk membeli barang dari luar negeri. Tidak hanya dari sisi perubahan gaya hidup konsumen, industri e-commerce juga membuka lebih banyak peluang bisnis baru, serta menghasilkan dampak beruntun (trickle-effect) bagi industri di sektor pendukung, seperti logistik, infrastruktur IT, dan operator e-commerce. Ditemukan beberapa platform digital yang paling banyak digunakan oleh pembeli online asal Indonesia seperti Shopie, Bukalapak, Tokopedia, Lazada, Blibi.com, dan lainnya. Penggunaan platform tersebut untuk belanja peralatan elektronik seperti telepon seluler, kamera, laptop, dan komputer. Selain itu produk aksesori elektronik, seperti audio, printer, penyimpanan data, hingga aksesori Handphone. Data Kementerian Perindustrian, 90 persen barang yang dijual secara online merupakan produk impor. Hal ini membuat persaingan semakin ketat,". Saat ini dunia memasuki era perdagangan tanpa batas, pergerakan barang dan jasa menjadi sangat mudah. Dampaknya, impor barang melalui ecommerce meningkat tajam. (Pranata, 2019).

Data survey lainnya tahun 2018 oleh APJII (Asosiasi Pengguna Jasa Internet Indonesia) pengguna internet di Indonesia berdasarkan katagori usia didominasi oleh usia 15-19 tahun dengan persentase sebesar 91\%, milenial merupakan kelompok orang yang lahir pada awal tahun 1980-an hingga awal 2000-an. Usia milenial lainnya yang merajai posisi teratas lainnya soal pengguna internet RI ini, yaitu 20-24 tahun dengan penetrasi 88,5\%. emudian di bawahnya ada kelompok umur 25-29 tahun dengan penetrasi 82,7\%, kelompok umur 30-34 tahun dengan penetrasi 76,5\%, dan kelompok umur 35-39 tahun dengan penetrasi 68,5\%. dari total populasi penduduk yang mencapai 264,14 juta orang ternyata ada 171,17 juta di antaranya yang terhubung 
jaringan internet sepanjang 2018. Dibandingkan tahun sebelumnya, ada pertumbuhan 27,9 juta pengguna internet di 2018. Generasi millennial dideskripsikan sebagai kelompok generasi yang lahir diantara tahun 1980 dan 2000. Menurut (Goldman Sachs Global Investment Research, 2017) dalam (P et al. 2016). Berdasarkan pernyataan tersebut dapat dikatakan generasi millennial merupakan generasi dengan kisaran usia 19-39 tahun. Dengan demikian dapat dikatakan generasi millennial dekat dengan perkembangan internet dan bisa dengan mudah mengadopsi budaya transaksi online yang ada saat ini.

Budaya sebagai salah satu konstruksi paling abstrak yang mempengaruhi perilaku manusia, telah dijelaskan dan didefinisikan dalam banyak cara. Perilaku konsumen yang terbentuk dalam budaya di negara atau di daerah tertentu akan berpengaruh dalam menunjukan niat beli dari suatu produk. Uncertainty Avoidance mengarah kepada ketidakpastian dan ambigius, dalam hal ini sebagian konsumen tidak mau mengambil resiko jika produk yang dijual tidak pasti dan ambigu karena produk yang dijual tidak bisa dijangkau dan sistemnya menggunakan internet (Gong 2009).

Dalam melakukan transaksi konsumen akan mempertimbangkan pilihan terhadap produk yang akan mereka beli. Harga merupakan faktor penting dalam mempengaruhi niat pembelian konsumen. Ketika suatu perusahaan menggunakan permintaan konsumen yang lebih tinggi untuk keuntungannya sendiri dengan menaikkan harga, konsumen akan merasa dieksploitasi dan karenanya menganggap harga itu tidak adil (Herrmann et al. 2007). Produk luar negeri yang di jual di Shopie, Bukalapak, Tokopedia, Lazada, dan Blibi.com (markerplace) memilki harga yang kompetitif dengan harga produk dari penjual lokal. Sebagian konsumen ingin memenuhi kebutuhannya dengan memilih produk bagus dengan harga yang sesuai, dengan adanya produk dari luar negeri yang ada pada markerplace diharapkan mampu memenuhi kebutuhan konsumen. Harga merupakan faktor penting dalam mempengaruhi niat pembelian konsumen. Produk luar negeri yang di jual di markerplace relatif lebih rendah dibandingkan harga yang dijual oleh produk lokal. Harga yang rendah tersebut merupakan harga dari distributor langsung dan dikirim dari China. Hal ini dilihat bahwa sebagian konsumen lebih memprioritaskan harga dibandingkan dengan kualitas produk yang dijual. Selain harga yang ditetapkan oleh penjual online, faktor lain yang mempengaruhi kepercayaan agar membentuk niat pembelian pada konsumen adalah reputasi perusahaan. Reputasi markerplace sebagai e-commerce yang ada di Indonesia sangatlah berpengaruh untuk menarik niat konsumen. Reputasi perusahaan didefinisikan sebagai persepsi pelanggan tentang caranya baik perusahaan mengurus pelanggan dan benar-benar prihatin tentang kesejahteraan mereka ( Hess, Ronald L. 2008). Dalam menjaga reputasi, penjual online harus menjelaskan deskripsi produk dengan jelas dan detail. Kualitas pada produk juga harus diperhatikan para penjual produk luar negeri untuk meningkatkan kepercayaan konsumen. Proses 
pemesanan sampai produk diterima pelanggan harus diperhatikan, sehingga feedback yang didapat adalah positif. Feedback yang diberikan konsumen adalah feedback positif dan negatif yang pada akhirnya akan berpengaruh pada tingkat pembelian dan berpengaruh pada reputasi Shopee, Bukalapak, Tokopedia, Lazada, dan Blibi.com.com sebagai ecommerce yang menyediakan produk yang dikirim dari luar negeri khususnya dari China.

Tujuan penelitian ini untuk menguji kepercayaan yang saling berkesinambungan antara kepercayaan konsumen terhadap markerplace sebagai penyedia vendor penjualan online produk dari luar negeri dalam melakukan transaksi melalui online yang menyebabkan niat pembelian konsumen, khususnya pada konsumen millennial yang dekat dengan perkembangan internet dan menerima informasi baru dalam melakukan transaksi online. Kepercayaan sebagai konstruk multidimensi yang terdiri dari kepercayaan yang dapat dipercaya (trusting beliefs) dan niat untuk mempercayai, dan di samping itu atribut trusting beliefs terdiri dari integritas, kebajikan dan kompetensi dan juga dikaitkan dengan niat konsumen untuk berbelanja online (Mcknight, Cummings, and Chervany 1998). Kepercayaan dalam penelitian ini di batasi pada integritas, kebijakan dan kompetensi pada markerplace sebagai e-commerce dalam menarik niat beli konsumen. Tentunya bukan hal yang mudah bagi markerplace untuk meningkatkan kepercayaan konsumen millennial, hal ini menjadi tantangan yang sangat besar di tengah maraknya ecommerce yang tumbuh pesat di Indonesia namun tidak semua e-commerce yang menjual produk dari luar negeri. Vendor online yang menjual produk luar negeri merupakan penjual dari luar negeri juga yang bekerja sama dengan markerplace. Pastinya ada perbedaan persepsi dan tingkat kepercayaan yang dirasakan dalam pengambilan keputusan pembelian terhadap produk lokal dan produk dari luar negeri.

\section{LITERATUR DAN HIPOTESIS}

Komponen yang paling penting dari pembelian online adalah kepercayaan dari pelanggan ke toko online itu sendiri (Giantari et al., 2013; Rose et al., 2012; Shobeiri et al., 2014; dan McKnight et al. (1998, p. 487). Trusting beliefs yaitu, kemampuan, kebajikan, kompetensi dan prediktabilitas, sebagai komponen kunci untuk menciptakan kepercayaan. Keyakinan mempercayai dianggap sebagai esensi dari kepercayaan yang memfasilitasi persepsi tentang karakter etis atau perilaku moral dari setiap vendor (Ring dan Van de Ven, 1994). Dengan demikian, kepercayaan mempercayai adalah jaminan bahwa vendor tersebut menampilkan sifat-sifat yang menguntungkan untuk mendorong niat mempercayai.

Salah satu premis utama yang terwujud dari pekerjaan sebelumnya adalah bahwa Uncertainty avoidance penting dalam kaitannya dengan niat masa depan (Doney dan Cannon, 1997) 
dan jika vendor online memiliki reputasi positif maka kepercayaan di mata pelanggan meningkat (Koufaris dan Hampton-Sosa , 2004), sehingga mengurangi ketidakpastian.

\section{Uncertainty Avoidance}

Uncertainty avoidance mengacu pada sejauh mana anggota budaya merasa terancam oleh situasi yang tidak pasti atau tidak diketahui (Hofstede, 2001). Individu dalam budaya uncertainty avoidance tinggi menunjukkan toleransi yang lebih rendah untuk ambiguitas dan keragaman daripada mereka yang berada di budaya uncertainty avoidance rendah (Hofstede, 2004). Dengan demikian, mereka lebih cenderung memilih struktur, yang membuat peristiwa lebih mudah ditafsirkan dan diprediksi. Sebaliknya, orang-orang dari budaya uncertainty avoidance rendah relatif lebih nyaman dengan ambiguitas dan lebih toleran terhadap keanekaragaman. Hwang (2009) berpendapat bahwa uncertainty avoidance mempengaruhi perilaku yang baik dan dimensi kemampuan kepercayaan online sambil mengabaikan integritas, sehingga kepercayaan pada vendor online mengurangi risiko, yang pada gilirannya mengurangi kompleksitas sosial dan ketidakpastian dalam transaksi online. dalam konteks yang sama, Kailani dan Kumar (2011) mengusulkan bahwa ada keselarasan antara uncertainty avoidance dan risiko yang dirasakan dan pembelian internet, dan menemukan bahwa individu dari budaya dengan tingkat uncertainty avoidance tinggi lebih mungkin mengalami peningkatan level risiko yang dirasakan ketika melakukan pembelian melalui marketplace.

Price Fainess

Price Fainess, menurut Kotler dan Keller (2012), menyatakan harga harus mencerminkan nilai konsumen bersedia membayar harga dibandingkan harus mencerminkan hanya biaya pembuatan produk atau memberikan layanan. Artinya harga merupakan sejumlah uang yang dibutuhkan atau ditukarkan ke konsumen untuk mendapatkan atau memiliki suatu barang yang memiliki manfaat serta penggunaannya. Di samping itu harga merupakan unsur bauran pemasaran yang bersifat fleksibel, artinya dapat diubah dengan cepat (Tjiptono, 2008). Dari sudut pandang pemasaran, harga merupakan satuan moneter atau ukuran lainnya (termasuk barang dan jasa lainnya) yang ditukarkan agar memperoleh hak kepemilikan atau penggunaan suatu barang atau jasa (Tjiptono, 2008). Harga khususnya merupakan pertukaran uang bagi barang atau jasa. Juga pengorbanan waktu karena menunggu untuk memperoleh barang atau jasa (Lupiyoadi, 2001).

\section{Firm's Reputation}

Reputasi perusahaan didefinisikan sebagai persepsi pelanggan tentang seberapa baik suatu perusahaan menangani pelanggan dan benar-benar peduli dengan kesejahteraan pelanggan (Doney dan Cannon, 1997). Reputasi perusahaan telah terbukti mempengaruhi banyak respon 
pelanggan, termasuk pilihan produk dan layanan, sikap keseluruhan (Brown. T.J., A. D Peter, M.G Pratt, and D.A. Whetten. 2006), niat beli, dan kepercayaan (Johnson dan Grayson, 2005) .(Walsh et al, 2008: 4) mendefinisikan reputasi perusahaan sebagai sebuah evaluasi keseluruhan yang dilakukan oleh stakeholders terhadap perusahaan dari waktu ke waktu. Evaluasi tersebut didasarkan pada pengalaman langsung dari para stakeholder terhadap perusahaan, bentuk lain dari komunikasi dan simbolisme yang menyediakan informasi mengenai aksi/ tindakan perusahaan dan/atau pembandingan dengan aksi/tindakan yang dilakukan pesaing utamanya.) Reputasi perusahaan adalah asosiasi mental mengenai organisasi yang dipikirkan oleh orang-orang diluar organisasi (Brown et al., 2006: 102). Berdasarkan definisi tersebut, Brown mencoba menjelaskan bahwa reputasi merujuk pada apa yang dipikirkan oleh para stakeholder mengenai organisasi.

\section{Trusting Belief}

Menurut Moorman et al yang dikutip oleh (Darsono ,2008), kepercayaan adalah suatu kesediaan individu untuk menggantungkan dirinya pada pihak lain yang terlibat dalam pertukaran karena individu mempunyai keyakinan kepada pihak lain. Sementara itu, Mowen dan Minor (2002) menyatakan bahwa kepercayaan merupakan semua pengetahuan yang dimiliki konsumen dan semua kesimpulan yang dibuat tentang objek, atribut, dan manfaatnya. (Swaniathan dan Reddy dalam John Eagen ,2004) menyatakan bahwa kepercayaan juga merupakan psychological outcome dari suatu hubungan. Teori Trusting Belief, adalah atribut kepercayaan dari trustee adalah kemampuan, kebajikan, dan integritas (Mayer dkk ,1995). McKnight dan Chervany (2001) menyoroti Trusting Belief sebagai reaksi kognitif dan afektif yang dihasilkan setelah interaksi trustor dan trustee, dan reaksi ini menentukan sikap saling percaya dan saling percaya tingkah laku. Dengan demikian dapat disimpulkan bahwa trusting belief yang dimaksud bukan hanya sebatas kepercayaan yang diyakini oleh konsumen terhadap suatu produk saja, namun merupakan kepercayaan dari segala aspek yang dimiliki oleh perusahaan terhadap produk yang ditawarkan, dari mulai konsumen melakukan transaksi hingga transaksi selesai, perusahaan ingin memberikan pelayanan terbaik bagi konsumen agar konsumen merasa dilayani dengan baik sehingga memiliki kepercayaan yang berkesinambungan dari semua aspek dalam sebuah transaksi dari awal dan akhir transaksi.

\section{Purchase Intentions}

Purchase intentions timbul setelah adanya proses evaluasi alternatif (Kotler, Bowen dan Makens, 2014). Dalam proses evaluasi, seseorang akan membuat suatu rangkaian pilihan mengenai produk yang hendak dibeli atas dasar merek maupun niat. Sedangkan intention (niat) itu sendiri adalah tingkat dimana memungkinkan konsumen untuk melakukan pembelian dalam waktu yang akan datang dan purchase intention merupakan kemungkinan bahwa pelanggan akan merencanakan atau bersedia untuk membeli produk atau jasa tertentu. Atas dasar niat pembelian 
oleh konsumen sehingga adanya nilai yang dirasakan konsumen yaitu penilaian lengkap dari konsumen akan biaya dan manfaat dari penawaran bersih yang dimiliki konsumen dari penerapan pemasaran yang dilakukan perusahaan. Purchase intention merupakan salah satu bagian dari komponen dalam sikap konsumen mengkonsumsi suatu produk. Purchase intention menurut Kinnear dan Taylor (2003) adalah tahap kecenderungan responden untuk bertindak sebelum keputusan membeli benar-benar dilaksanakan, sedangkan menurut Simamora (2002) niat beli adalah sesuatu yang pribadi dan berhubungan dengan sikap individu yang berniat pada suatu objek akan mempunyai kekuatan atau dorongan untuk melakukan serangkaian tingkah laku untuk mendekati atau mendapatkan objek tersebut. Dengan demikian dari pengertian diatas dapat disimpulkan bahwa Purchase intention merupakan suatu sikap yang akan merespon ketertarikan seorang konsumen terhadap produk yang akan dibeli.

\section{Trusting beliefs dan Purchase Intentions}

Penelitian yang telah dilakukan untuk menganalisis hubungan antara kepercayaan dan PI (Chen dan Chang-Hsun, 2012; Chen dan Barnes, 2007); UA dan pembelian internet (misalnya Kailani dan Kumar, 2011); citra perusahaan dan niat perilaku (misalnya Hsu et al., 2010); dan persepsi harga dan PI pelanggan (Kalapurakal et al., 1991). Seiring dengan hal tersebut di atas, ada penelitian yang mencerahkan hubungan antara kepercayaan dan niat mempercayai (Becerra dan Korgaonkar, 2009). Selain itu, Salo dan Karjaluoto (2007) mengeksplorasi faktor internal dan eksternal yang mempengaruhi kepercayaan percaya; Namun, mereka tidak menganalisis dampak harga terhadap kepercayaan yang dipercaya. Mengingat kekurangannya, timbul kebutuhan untuk memeriksa faktor-faktor penting lainnya yang mungkin berdampak besar pada kepercayaan yang dipercaya, terutama di pasar yang sedang berkembang. Penetiliti laninya tentang pemahaman peran yang dimainkan oleh trusting belief saat terlibat dengan penjualan online ( Sahi, Gurjeet Kaur Sekhon, Harjit Singh Quareshi, Tahira Khanam 2016). Hal ini yang dijadikan model penelitian menggunakan model penelitian, karena adanya kecocokan variabel yang akan diteliti dengan objek penelitian.

\section{Generasi Millennial}

Generasi Millennial, dideskripsikan sebagai kelompok generasi yang lahir diantara tahun 1980 dan 2000 (Goldman Sachs Global Investment Research, 2017). Menurut Shiffman \& Kanuk (2007:245) Fase penting yang terjadi saat generasi millenial tumbuh adalah perkembangan teknologi yang memasuki kehidupan sehari-hari. Sedangkan ciri dari generasi ini adalah tingkat pendidikan dan pengetahuan yang lebih baik dari generasi sebelumnya. Terdapat keberagaman dari segi etnik yang lebih baik dari generasi sebelumnya. Generasi millennial sering dinamai echoboomers atau millennium generation. Nama echo boomers hadir karena mereka yang termasuk dalam generasi ini adalah generasi yang lahir pada masa perang dunia II. Sedangkan dinamai 
millennium generation karena mereka merasakan perkembangan teknologi dan pergantian tahun millennium.

Oleh karena itu, penelitian ini mengisi kesenjangan penelitian ini dengan mempertimbangkan UA, FR dan PF sebagai prediktor trusting belief. Selain itu, penelitian yang disajikan di sini menganalisis peran trusting belief dalam kaitannya dengan Purchase Intentions (Gambar 1).

\section{Trusting Belief dan Uncertainty Avoidance}

Kailani dan Kumar (2011) mengusulkan bahwa ada keselarasan antara uncertainty avoidance dan risiko yang dirasakan dan pembelian internet, dan menemukan bahwa individu dari budaya dengan tingkat uncertainty avoidance tinggi lebih mungkin mengalami peningkatan level risiko yang dirasakan ketika melakukan pembelian melalui platform internet. Temuan dari budaya yang mendapat skor tinggi pada uncertainty avoidance mengungkapkan bahwa individu-individu dalam budaya tersebut cenderung melakukan pembelian melalui internet. Demikian juga, Vance et al. (2008) menyoroti pengaruh signifikan budaya uncertainty avoidance pada kepercayaan dan keyakinan. Dengan demikian, berdasarkan argumen sebelumnya kami mengusulkan bahwa:

\section{H1: Uncertainty Avoidance memiliki pengaruh negative terhadap Trusting Belief.}

\section{Trusting beliefs and Price Fairness}

Peneliti perilaku berpendapat bahwa persepsi pelanggan tentang ketidakmerataan harga dinamis memiliki efek negatif pada kepercayaan konsumen dan repurchase (Garbarino dan Lee, 2003). Demikian juga, penelitian sebelumnya telah menunjukkan bahwa persepsi harga yang tidak adil mempengaruhi kepuasan pelanggan dan purchase intentions (Campbell, 1999). Dalam hal ini, Grewal et. al. (2004) mendukung hubungan antara persepsi dan kepercayaan, price fairness and repurchase dan mengungkapkan bahwa konsumen melihat perbedaan harga yang lebih besar sebagai lebih tidak adil. Demikian pula, White and Yuan (2011) dan Kim et.all. (2012) mengedepankan hubungan antara harga, kepercayaan, kepercayaan kepercayaan dan purchase intentions dan berpendapat bahwa dengan mengurangi harga, kepercayaan yang dirasakan dapat meningkatkan kemampuan akuisisi dan transparansi transaksi, yang kemudian menghasilkan purchase Intentions pelanggan. Ini, berdasarkan literatur yang disebutkan di atas kami mengusulkan bahwa:

H2: Price Fairness memiliki pengaruh positif dan signifikan terhadap Trusting Belief 


\section{Trusting beliefs and Firm Reputation}

Firm reputation adalah representasi perseptual dari tindakan mereka di masa lalu dan prospek masa depan yang menggambarkan penampilan perusahaan pada konstituen utamanya (Fombrun, 1996, p.165). Jika pelanggan memiliki persepsi yang baik tentang reputasi vendor, kredibilitas vendor online meningkat dan secara bersamaan, kepercayaan pada vendor online juga meningkat (Ganesan, 1994). Adanya hubungan positif yang signifikan antara reputasi perusahaan dan trusting beliefs serta pada Purchase Intentions (Mcknight et al. 2002).

\section{H3: Firm Reputation memiliki pengaruh positif dan signifikan terhadap Trusting Belief} pada hasil penelitian ini

\section{Trusting beliefs dan Purchase Intentions}

Ketika melakukan pembelian online, trusting beliefs memiliki peran penting bagi vendor online (Pan and Chiou 2011). Sedangkan (Mayer, Davis, and Schoorman 1995) mengemukakan bahwa atribut kepercayaan dari trustee adalah kemampuan, kebajikan dan integritas. (Sahi, Sekhon, and Quareshi 2016) mengungkapkan pengaruh kehadiran sosial pada dimensi-dimensi trusting beliefs, terutama pada kebajikan dan kontribusi utamanya pada purchase intention online. Dengan demikian trusting beliefs adalah persepsi tentang kepercayaan, dan perusahaan yang memiliki sifat-sifat dimensi trusting beliefs lebih diinginkan sebagai penukar karena mereka akan memiliki hubungan yang adil, ramah, mahir, dan konsisten dalam transaksi pertukaran. Dalam penelitian (McKnight and Chervany 2001) menyoroti trusting beliefs sebagai reaksi kognitif dan afektif yang dihasilkan setelah interaksi trustor dan trustee, dan reaksi ini menentukan sikap saling percaya dan tingkah laku saling percaya. Dengan demikian, kepercayaan yang tinggi menyebabkan konsumen untuk mau bergantung pada vendor online, maka dapat disimpulkan:

H4: Trusting beliefs pada vendor online berhubungan positif dengan purchase intentions

\section{Model Hipotesis}

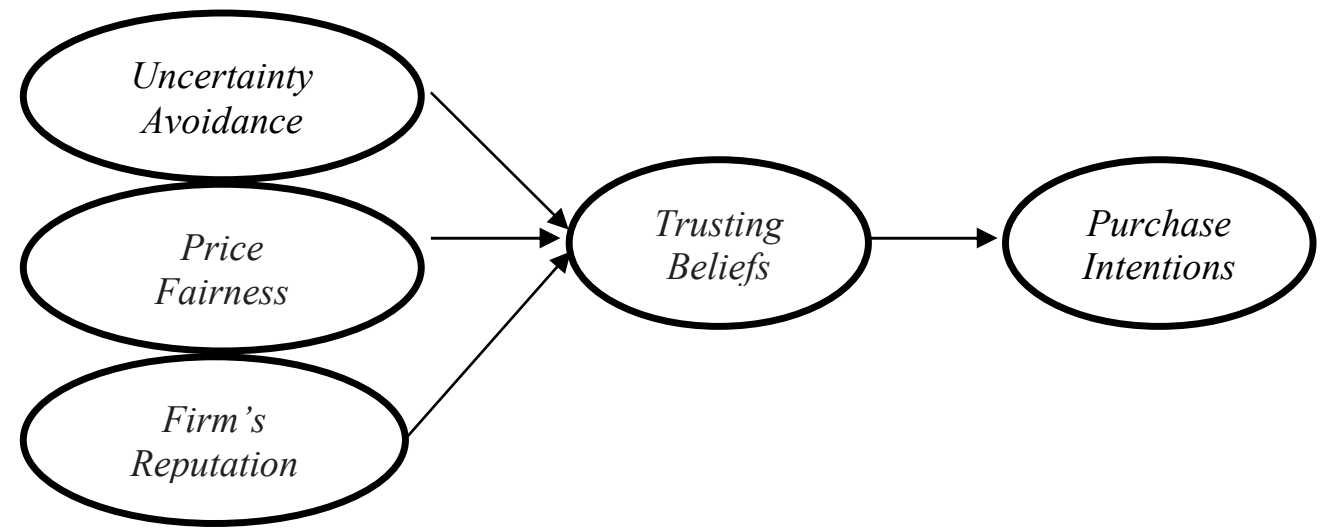

Gambar 1

Sumber: Sahi, Sekhon, dan Quareshi 2016 


\section{DATA DAN METODE}

Objek dalam penelitian ini adalah konsumen Shopee, Lazada Indonesia, Tokopedia, Bukalapak, dan Blibli merupakan sebuah platform yang dirancang khusus untuk menyuguhkan pengalaman berbelanja online dengan menawarkan produk yang dijual dari luar negeri untuk memenuhi kebutuhan konsumen. Responden pada penelitian ini Konsumen platform dengan krteria konsumen millennial, konsumen mengetahui produk luar negeri yang di jual platform, dan konsumen yang tidak pernah transaksi produk dari luar negeri pada platform tersebut. Generasi Millennial dideskripsikan sebagai kelompok generasi yang lahir diantara tahun 1980 dan 2000 (Goldman Sachs Global Investment Research, 2017) sehingga objek penelitian ini ditunjukan kepada konsumen platform di Jabodetabek dengan kisaran usia 19-39 tahun.

Desain penelitian memiliki definisi sebagai sebuah kerangka kerja yang digunakan dalam melakukan sebuah penelitaian, desain penelitian memberikan serangkaian prosedur yang diperlukan untuk memperoleh informasi yang terstruktur untuk dapat menjawab permasalahan penelitian (Malhotra 2012). Jenis penelitian yang digunakan adalah penelitian eksplanatif penelitian tersebut merupakan jenis penelitian yang dirancang untuk membantu keputusan dalam menentukan, mengevaluasi, dan memilih alternatif terbaik dalam memecahkan masalah. Pada penelitian ini peneliti menggunakan penelitian deskriptif kuantitatif yang akan dilakukan satu kali dalam satu periode (cross sectional design). Cross sectional design adalah jenis rancangan riset yang terdiri dari pengumpulan informasi mengenai sampel tertentu dari elemen populasi hanya sekali (Malhotra 2012).

Sumber data yang digunakan dalam penelitian ini berasal dari dua sumber yaitu data primer dan data sekunder. Data yang digunakana diharapkan sesuai dengan permasalahan yang dihadapai sehingga dapat menjawab hipotesis dari penelitian ini dan dapat menyelesaikan permasalahan penelitia. Data primer dihasilkan langsung oleh peneliti untuk tujuan tertentu dalam menjawab permasalahan penelitian (Malhotra 2012). Pada penelitian ini data primer dikumpulkan dengan metode survey yang menggunakana kuesioner sesuai dengan penbelitian ini, kuesioner akan dibagikan secara online kepada responden yang merupakan konsumen millennial dalam niat pembelian produk luar negeri yang di jual pada platform Shopee, Lazada Indonesia, Tokopedia, Bukalapak, dan Blibli ( Platform). Kuesioner yang dibuat oleh peneliti dengan menggunakan skala Likert 6 poin yaitu skala pengukuran dengan enam kategori respon yang berkisar antara sangat tidak setuju (=1) dan sangat setuju (=6) yang mengharuskan responden menentukan derajat persetujuan atau ketidaksetujuan mereka terhadap masing-masing dari pertanyaan mengenai objek stimulus (Malhotra 2010). Data Sekunder merupakan data yang dikumpulkan oleh pihak lain dari berbagai sumber, seperti buku-buku, media internet, serta jurnal jurnal penelitian sebelumnya 
yang signifikan dengan topic penelitian (Malhotra 2012). Pada penelitian ini data sekunder didapat dari buku pendukung yang berhubungan dengan penelitian, jurnal penelitian sebelumnya, informasi dari internet mengenai berita berita yang terkait dengan masalah penelitian ini.

Populasi dan Sampel, Populasi merupakan kumpulan elemen yang ingin dibuat dari beberapa kesimpulan, sedangkan sempel adalah elemen bagian dari populasi yang dipilih sebagai partisipan didalam sebuah percobaan (Cooper and Schindler 2011). Populasi penelitian ini adalah masyarakat Jabodetabek yang merupakan kaum millennial yang melakukan pembelian produk luar negeri secara online yang di jual di platform Shopee, Lazada Indonesia, Tokopedia, Bukalapak, dan Blibli (Platform).. Metode sampling yang digunakan adalah non-probability sampling dengan teknik convenience. Teknik convenience adalah teknik pengambilan sampel dengan cara random pemilihan responden yang tersedia dan mudah diakses (Malhotra 2010). Penggunaan convenience digunakan oleh peneliti karena lebih murah dan lebih menghemat waktu dibandingkan dengan metode pengambilan sampel lain (Malhotra 2010). Di dalam penelitian ini terdapat 22 indikator. Pada penelitian ini sampel yang digunakan adalah jumlah pelanggan yang terdiri dari millennial yang berbelanja produk luar negeri di platform OL. Sesuai dengan pedoman ukuran sampel menurut (Hair et al. 2010) yang menyatakan pedoman ukuran sampel tergantung pada ( jumlah indikator X 5 ). Peneliti menggunakan perkalian 5 di karenakan mengantisipasi adanya jawaban responden yang lebih luas. Maka dalam penelitian ini jumlah sampelnya sebagai berikut :

$$
\text { Jumlah sampel }=22 \times 5=110
$$

Data digunakan melalui online survey Google Form dengan jumlah sampel yang diambil dalam penelitian ini adalah 110 responden.

Variabel dan Operasional Variabel dalam penelitian ini pengukuran data yang digunakan adalah pengumpulan data menggunakan instrumen kuisioner yang diadopsi berdasarkan kuisioner dalam penelitian sebelumnya. Menurut (Malhotra 2010) skala likert adalah skala yang digunakan secara luas yang meminta responden menandai derajat persetujuan atau ketidak setujuan terhadap masing-masing dari serangkaian pernyataan mengenai obyek stimulus. Alat ukur dalam penelitian ini menggunakan skala likert dengan rentang 1-6, dimana responden diberikan pertanyaan mengenai seberapa besar pendapat mereka atas pertanyaan-pertanyaan dalam kuesioner, dimana jawaban poin 1 menunjukkan skala yang sangat tidak setuju dan jawaban poin 6 menunjukkan skala yang sangat setuju

Trusting Beliefs, menurut (Sekhon et al. 2014) atribut kepercayaan terdiri dari:

1. Kemampuan (competencies) yaitu mengacu pada keterampilan, kompetensi, dan karakteristik perusahaan.

2. Kebajikan (benevolence) adalah sejauh mana perusahaan dipercaya melakukan kebaikan. 
3. Integritas (integrity) mengacu pada konsistensi tindakan masa lalu perusahaan dan komunikasi yang kredibel

Uncertainty Avoidance (UA), menurut Hofstede (2001) dalam (Lee, Garbarino, and Lerman 2007) uncertainty avoidance yaitu mengacu pada sejauh mana anggota budaya merasa terancam oleh situasi yang tidak pasti atau tidak diketahui. Firm's Reputation ( FR ), menurut (Doney and Cannon 1997) reputasi perusahaan didefinisikan sebagai persepsi pelanggan tentang seberapa baik suatu perusahaan menangani pelanggan dan benar-benar peduli dengan kesejahteraan pelanggan. Price Fairness ( PF ), menurut (DesJardins 2009) menganggap bahwa Price fairness adalah harga yang adil hasil dari kesepakatan yang dicapai antara pembeli dan penjual. Purchase Intentions (PI), menurut (Simamora 2002) Purchase intentions adalah sesuatu yang pribadi dan berhubungan dengan sikap individu yang berniat pada suatu objek akan mempunyai kekuatan atau dorongan untuk melakukan serangkaian tingkah laku untuk mendekati atau mendapatkan objek tersebut.

Analisis Data

Pada penelitian ini peneliti menggunakan metode analisis SEM (Structural Equation Models). Menurut (Santoso, 2012) SEM merupakan kombinasi antara analisis faktor dan analisis regresi (kolerasi) yang bertujuan untuk mengoreksi hubungan antar variable yang ada pada sebuah model, baik itu antar indikator dengan konstruknya, ataupun hubungan antar konstruknya. Untuk membantu analisis model SEM pada penginputan data menggunakan software AMOS 22 for Windos. Menurut (Wijanto, 2008) ada beberapa tahapan yang dilalui ketika menggunakan SEM, yaitu sebagai berikut :

1. Spesifikasi Model (Model Spesification)

2. Indentifikasi (Identification)

3. Estimasi (Estimation)

4. Uji Kecocokan ( Testing Fit)

SEM terdiri dari 2 bagian yaitu model variable laten dan model dan model pengukuran. Kedua model SEM ini mempunyai karakteristik yang berbeda dengan regresi biasa. Regresi biasa umumnya memspesifikasikan hubungan kausal antara variable variable teramati (observed variable), sedangkan pada model variable SEM, hubungan kasual terjadi diantara variable variable tidak teramati (unobserved variables) atau variabel - variabel laten.

Spesifikasi Model ( Model Spesification), Spesifikasi model adalah langkah pertama dalam metode SEM. Dalam penelitian ini Uncertainty Avoidance, Price Fairness, dan Firm's Reputation berperan sebagai variabel eksogen, trusting beliefs berperan sebagai variabel eksogen dan endogen. Sedangkan Purchase Intention berperan sebagai variable endogen. Setiap variabel 
laten baik eksogen dan endogen memiliki variabel teramati yang merupakan alat ukur dari masingmasing variabel. Di penelitian ini terdapat 22 variabel teramati yang merupakan indikator.

\section{HASIL DAN PEMBAHASAN}

Berdasarkan kuesioner yang disebar diperoleh 182 responden, tetapi yang terpakai untuk proses analisis data hanya 110 responden, 72 responden karena tidak sesuai dengan kreteria pertanyaan screening dalam penelitian. Responden tersebut bukan konsumen dan tidak pernah bertransaksi di marketplace, tidak mengetaui produk luar negeri dan sebagian sudah pernah membeli produk luar negeri yang ada di marketplace. Oleh karena itu data kuesioner yang memenuhi kriteria penelitian sebanyak 110 responden. Berdasarkan usia yang digunakan adalah usia berdasarkan generasi millennial. Responden dengan usia 19 - 25 tahun lebih mendominasi yaitu sebanyak 57 responden, dimana usia tersebut menunjukan konsumen yang aktif dalam bertransaksi menggunakan metode online. Diikuti responden usia 26 - 31 tahun sebanyak 40 responden dan usia 32 -39 tahun sebanyak 13 responden. Sementara berdasarkan data table 4.5 jenis kelamin responden didominasi oleh perempuan sebanyak 69 responden. Sedangkan responden dengan jenis kelamin laki - laki sebanyak 41 responden. Jumlah responden tersebut menunjukan responden merupakan konsumen pada platform dan mengetahui adanya produk luar negeri yang di jual di platform terbentuk namun mereka belum pernah membeli produk tersebut. Serta berdasarkan pendidikan terakhir responden didominasi pendidikan S1 sebanyak 54 responden, pendidikan SMA/ sederajat terdiri dari 20 responden, pendidikan D3 terdiri 32 responden, pendidikan S2 sebanyak 4 responden.

\section{Hasil Analisis Data}

Dalam penelitian ini peneliti menggunakan metode pengolahan data menggunakan Structural Equation Modeling (SEM) dengan software AMOS 22 peneliti juga menggunakan SPSS 26 untuk membantu dalam proses pengolahan data pada penelitian ini.

Spesifikasi Model, Spesifikasi model merupakan langkah pertama yang dilakukan dalam pengolahan data pada SEM sesuai dengan penjelasan sebelumnya. Dalam penelitian ini spesifikasi model terdiri dari 5 variabel, 4 hipotetsis, dan 22 indikator.

\section{Identifikasi Model}

Langkah selanjutkan setelah menentukan spesifikasi model adalah identifikasi model. Identifikasi model dapat dilakukan pada SEM jika model penelitian termasuk dalam kategori over - identified dimana kategori tersebut ditentukan dengan hasil dari data degree of freedom, yang menunjukan hasil data degree of freedom sebesar 182 (positif). Dengan demikian identifikasi model dalam penelitian ini termasuk dalam kategori over - identified karena memiliki nilai positif, sehingga penelitian ini dapat dilanjutkan. 
Uji Validitas dan Realibilitas. Suatu variable dapat dikatakan memiliki validitas yang baik jika memenuhi faktor standarnya (standardized loading factors) $\geq 0,50$ dan idealnya $\geq 0,70$ (Hair et al. 2010). Data yang dikatakan reliabilitasnya tinggi yaitu indikator - indikator yang mempunyai konsistensi tinggi dalam mengukur konstruk latennya. Untuk Mengukur reliabilitas dalam metode SEM akan digunakan composite reliability measure dan variance extracted measure, sebuah konstruk mempunyai reliabilitas yang baik jika nilai construct reliability $(\mathrm{CR}) \geq 0,70$ dan variance extracted $(A V E) \geq 0,50$ (Hair et al. 2010). Berdasarkan hasil data pada tabel 4.8 hasil uji validitas dan reliabilitas menunjukan 1 indikator yang tidak valid yaitu indikator COM 2 pada variabel trusting beliefs dengan niali factor loading sebesar 0,494 dimana nilai tersebut dibawah variance extracted (AVE) 0,50. Maka peneliti menguji data kembali agar data bisa diterima dengan mengeluarkan indikator COM 2 pada variabel trusting beliefs dengan hasil sebagai berikut. Dari hasil pengujian menunjukan pengujian ulang dengan mengeluarkan indikator COM 2 dan menggunakan 21 data indikator agar data tetap bisa digunakan sebagai bahan penelitian. Dari hasil pengolahan data pada 21 indikator tersebut maka dapat dikatakan bahwa data valid karena sudah memenuhi kriteria dari validitas dengan nilai standardized loading factor $\geq 0.5$. Kemudian dapat dilihat pula dari tabel diatas, hasil pengolahan data pada setiap variable menunjukan nilai construct reliability $(\mathrm{CR}) \geq 0,70$, dan nilai variance extracted $(\mathrm{VE}) \geq 0,50$. Sehingga dapat disimpulkan secara keseluruhan nilai reliabilitas model pengukuran penelitian ini adalah baik serta indikator yang digunakan pada setiap variable mampu menjelaskan variable laten yang dibentuknya.

\section{Hasil Uji Model Keseluruhan (Overall Model Fit)}

\subsection{Godness Of Fit (GOF)}

Dalam melakukan uji model keseluruhan langkah awal yang dilakukan peneliti adalah mengevaluasi secara umum derajat kecocokan atau goodness of fit (GOF) antara data dengan model penelitian. Menilai GOF dengan menggunakan metode SEM secara keseluruhan tidak dapat dilakukan secara langsung seperti halnya teknik multivariate lainnya. Dalam hal ini metode SEM tidak memiliki satu uji statistic terbaik yang dapat menjelaskan prediksi ukuran kekuatan terhadap suatu model. Sebagi gantinya, para peneliti telah mengembangkan beberapa ukuran GOF yang dapat digunakan secara bersamaan atau kombinasi (Wijanto 2008). 


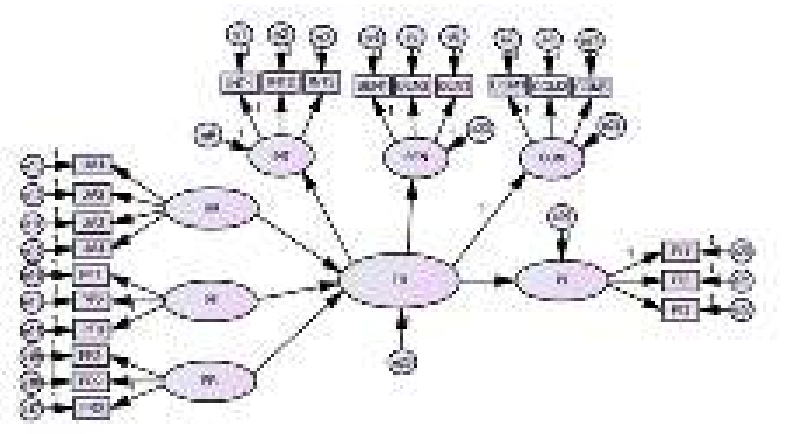

Gambar 3.1 Model Pengukuran

Sumber: Dikembangkan oleh peneliti dengan menggunakan AMOS 22

Berikut tabel dibawah ini yang menunjukan beberapa fit index untuk mencocokan model keseluruhan dengan menggunakan perhitungan SEM.

Tabel 1 Hasil Penelitian Goodness Of Fit

\begin{tabular}{c|c|c|c}
\hline GOF & Tingkat Kecocokan & $\begin{array}{c}\text { Hasil } \\
\text { Perhitungan }\end{array}$ & Kesimpulan \\
\hline CMIN/DF & CMIN/DF $\leq 3,00$ (good fit) & 2,382 & Good fit \\
\hline \multirow{3}{*}{ RMSEA } & $\begin{array}{c}\text { RMSEA } \leq 0,08 \text { (good fit) } \\
0,08 \leq \text { RMSEA } \leq 0,10 \\
\text { (marginal fit) } \\
\text { RMSEA } \geq 0,10 \text { (poor fit) }\end{array}$ & 0,113 & Poor fit \\
\hline CFI & $\begin{array}{c}\text { CFI } \geq 0,90 \text { (good fit) } \\
0,80 \leq \text { CFI } \leq 0,90 \\
(\text { marginal fit) }\end{array}$ & & \\
& CFI $\leq 0,80$ (poor fit) & & Marginal fit \\
\hline
\end{tabular}

Sumber : Hasil pengolahan dengan AMOS 22

Berdasarkan data dari tabel 4.10 menunjukan tiga ukuran GOF, terdiri dari CMIN/DF yang menunjukan kecocokan model yang baik (good fit) karena hasil analisis menunjukan nilai dibawah 3.33, RMSEA menunjukan kecocokan model yang kurang baik (poor fit) karena hasil analisis menunjukan nilai $\geq 0,10$ dan CFI menunjukan kecocokan model marginal fit karena hasil analisis menunjukan niali $\leq 0,90$.

\subsection{Hasil Analisis Model Keseluruhan (Overall Model Fit)}

Langkah selanjutnya yaitu menentukan model keseluruhan, model keseluruhan adalah seluruh hubungan antar konstruk yang memiliki hubungan kausal (sebab akibat) maka dari itu akan ada variable laten eksogen dan variable laten endogen. Analisis model keseluruhan berhubungan terhadap koefisien - koefisien atau parameter - parameter yang menunjukan hubungan kausal atau pengaruh variable laten terhadap variable laten lainnya, yang akan disesuaikan dengan kerangka model pada penelitian. Kemudian analisis model keseluruhan ini 
akan diketahui tingkat signifikan dengan cara melihat nilai $p$ pada hasil data penelitian. Jika nilai estimasi parameter menunjukan hasil positif dengan tingakat signifikansi $p<0,05$ maka hipotesis yang diajukan berarti didukung data. Namun, apabila sebaliknya jika nilai estimasi parameter menunjukan hasil negatif dengan tingkat signifikansi $p>0,05$ maka hipotesis yang diajukan tidak didukung oleh data. Hasil pengujian hipotesis pada model keseluruhan penelitian ini dapat dilihat pada tabel dibawah ini.

Tabel 2 Output Regression Weights

\begin{tabular}{c|c|c|c|c|c}
\hline Path & Estimate & S.E & C.R & P & Kesimpulan \\
\hline TB <--- PF & 0,405 & 0,123 & 3,293 & $* * *$ & Didukung data \\
\hline TB <--- FR & 0,630 & 0,096 & 6,547 & $* * *$ & Didukung data \\
\hline TB <--- UA & $-0,034$ & 0,063 & $-0,535$ & 0,593 & Tidak Didukung data \\
\hline PI <--- TB & 0,876 & 0,143 & 6,113 & $* * *$ & Didukung data \\
\hline
\end{tabular}

Sumber: Hasil pengolahan data dilakukan dengan peneliti dengan menggunakan AMOS 22

Berdasarkan tabel 2 hipotesis dalam penelitian ini dapat disimpulkan sebagai berikut :

1. Uncertainty Avoidance memiliki pengaruh negatif terhadap Trusting Beliefs.

Berdasarkan pada hasil pengujian data yang dilakukan dalam penelitian, diperoleh nilai estimasi sebesar $-0,034$ dengan nilai $p$ 0,593. Nilai estimasi tersebut menunjukan nilai estimasi yang negatif dengan nilai probabilitas lebih besar dari 0,05. Dengan demikian, Uncertainty Avoidance memiliki hubungan negatif dan tidak signifikan terhadap Trusting Beliefs dan hipotesis tidak diterima.

2. Price fairness memiliki pengaruh positif terhadap Trusting Beliefs.

Berdasarkan pada hasil pengujian data yang dilakukan dalam penelitian, diperoleh nilai estimasi sebesar 0,405 dengan nilai $p^{* * *}$. Nilai estimasi tersebut menunjukan nilai estimasi yang positif dengan nilai probabilitas lebih kecil dari 0,05. Dengan demikian, Price fairness memiliki hubungan positif signifikan terhadap Trusting Beliefs dan hipotesis dapat di terima.

3. Firm Reputation memiliki pengaruh positif terhadap Trusting Beliefs.

Berdasarkan pada hasil pengujian data yang dilakukan dalam penelitian, diperoleh nilai estimasi sebesar 0,630 dengan nilai $p^{* * *}$. Nilai estimasi tersebut menunjukan nilai estimasi yang positif dengan nilai probabilitas lebih kecil dari 0,05. Dengan demikian, Firm Reputation memiliki hubungan positif signifikan terhadap Trusting Beliefs dan hipotesis dapat di terima. 
4. Trusting Beliefs memiliki pengaruh positif terhadap Purchase Intention.

Berdasarkan pada hasil pengujian data yang dilakukan dalam penelitian, diperoleh nilai estimasi sebesar 0,876 dengan nilai $p^{* * *}$. Nilai estimasi tersebut menunjukan nilai estimasi yang positif dengan nilai probabilitas lebih kecil dari 0,05. Dengan demikian, Trusting Beliefs memiliki hubungan positif signifikan terhadap Purchase Intention dan hipotesis dapat di terima.

\section{Pembahasan}

Hasil analisis data pada penelitian ini menunjukan bahwa seluruh variabel sudah memenuhi kriteria konstruk validitas dan reliabilitas, serta model pengukuran lainnya yang sesuai dengan pengolahan data menggunakan metode SEM. Pada hasil dari hipotesis yang diajukan dalam model penelitian ini, tidak semua hipotesis memiliki pengaruh yang signifikan. Pembahasan dari hasil pengujian hipotesis akan dibahas sebagai berikut.

\subsection{Pengaruh price fairness terhadap trusting beliefs}

Hasil dari uji hipotesis dalam pengolahan data penelitian menunjukan bahwa price fairness berpengaruh positif dan signifikan terhadap trusting beliefs. platform menyediakan berbagai produk untuk memenuhi kebutuhan konsumen dengan menghadirkan penjual dari luar negeri. Harga produk yang dijual dari penjual luar negeri memiliki harga yang kompetitif dengan harga produk lokal, bahkan tidak jarang ditemukan harga produk luar negeri terbilang lebih murah. Sesuai dengan penelitian yang dilakukan oleh (Kim, Xu, and Gupta, 2012) bahwa harga merupakan sebagai komponen yang dijadikan kunci untuk memprediksi pilihan konsumen dan marketplace memberikan peluang besar untuk membandingkan harga antar vendor satu dengan vendor lainnya. Hal ini ditunjukan shopee ingin memberikan pengalaman bertransaksi yang mudah, dengan menggunakan aplikasi shopee konsumen dapat memfilter harga produk yang mereka cari dari mulai harga terendah sampai harga tertinggi. Dengan demikian konsumen dapat membandingkan harga suatu produk yang serupa dari penjual satu dengan penjual lainnya, sehingga konsumen mendapatkan banyak referensi produk yang dicari dan konsumen dapat menyesuaikan dengan harga yang dirasa sesuai dan adil.

Di dukung dengan penelitian yang dilakukan oleh (Sahi, Sekhon, and Quareshi, 2016) menunjukan price fairness memiliki pengaruh yang signifikan terhadapn trusting beliefs. Kemudahan yang diberikan shopee dalam membantu menentukan pilihan harga serta transaksi yang aman mempengaruhi secara langsung dan menjadi salah satu alasan konsumen memiliki niat beli terhadap produk luar negeri.

\subsection{Pengaruh firm reputatiom terhadap trusting beliefs.}


Hasil pengolahan data dalam penelitian didapatkan bahwa firm reputation berpengaruh positif dan signifikan terhadap trusting beliefs. Sesuai dengan peneletian yang dilakukan oleh (Ganesan, 1994) yaitu jika konsumen memegang persepsi yang menguntungkan dari reputasi vendor penjual online, kredibilitas vendor online meningkat dan pada akhirnya kepercayaan kepada vendor online juga meningkat. Generasi milenial merupakan generasi yang dekat dengan internet dan menerima adanya perubahan. Mereka merupakan konsumen yang memilih untuk melakukan transaksi secara online karena adanya keuntungan yang mereka rasakan secara langsung. Selain mudah dan lebih efisien bertransaksi melalui Platform memberikan keuntungan yang dapat dirasakan oleh konsumen seperti adanya promo gratis ongkir, voucher dan cashback, potongan harga dan promo menarik lainnya yang berlaku juga untuk pembelian produk dari penjual luar negeri. Selain itu shopee menjembatani semua proses transaksi dengan para penjual dari luar negeri sehingga konsumen tidak khawatir dalam melakukan pembelian produk tersebut karena mereka merasa terjamin dan aman ketika bertransaksi. Diperkuat dengan penelitian yanga dilakukan oleh (McKnight, Choudhury, and Kacmar, 2002) menunjukan adanya hubungan positif antara reputasi dan kepercayaan pelanggan dan menemukan bahwa reputasi yang dirasakan memiliki efek positif yang signifikan pada kepercayaan yang dipercayai, seperti juga pada niat mempercayai.

\subsection{Pengaruh uncertainty avoidance terhadap trusting beliefs.}

Berdasarkan hasil penelitian menunjukan bahwa uncertainty avoidance memiliki pengaruh yang negative dan tidak signifikan terhadap trusting beliefs. Hal ini menunjukan bahwa generasi millennial saat ini tidak menutup diri terhadap informasi baru dan teknologi yang sedang berkembang. Serta menerima budaya baru adanya perubahan dalam bertransaksi dari transaksi konvensional menjadi transaksi online. Hasil penelitian ini mendukung penelitian dari (Sahi, Sekhon, and Quareshi, 2016) Uncertainty Avoidance berhubungan negatif dengan trusting beliefs.

(Hofstede, 2004) menyatakan bahwa konsumen yang memiliki tingkat uncertainty avoidance tinggi mereka cenderung ragu - ragu terhadap produk baru. Platform mengeluarkan produk yang berlebel pengiriman dari luar negeri pada tahun 2017 dan masih terbilang baru. Meskipun terbilang baru konsumen millennial bisa dengan cepat mendapatkan informasi mengenai produk yang dijual dari luar negeri tersebut dan mereka memiliki niat beli yang cukup tinggi serta mau mencoba pengalaman baru dalam bertransaksi. Namun tidak dapat digeneralisir semua melenial dapat menerima informasi baru dan memiliki niat beli yang kuat terhadap produk dari luar negeri. Platform harus memberikan inovasi - inovasi yang baru untuk meyakinkan para konsumen milenial dengan cara menyediakan tampilan yang menarik dan memudahkan konsumen dalam menggunakan aplikasi, memberikan informasi yang jelas dan jujur dari penjual dalam mendeskripsikan produk yang dijual serta memberikan promo menarik seperti potongan harga, 
cashback dan promo lainnya, sehingga konsumen milenial tidak ragu untuk membeli produk dari luar negeri yang ada di Platform.

\subsection{Pengaruh trusting beliefs terhadap purchase intentions.}

Berdasarkan hasil penelitian menemukan bahwa trusting belief memiliki pengaruh yang positif dan signifikan terhadap purchase intentions. Platform menjembatani semua proses transaksi konsumen dengan para penjual dari luar negeri. Platform memonitori proses transaksi mulai dari konsumen melakukan pemesanan, proses pengiriman, dan sampai konsumen menerima produk yang dibeli. Jika ada kendala dalam proses transaksi Shopee menyediakan layanan customer service yang dapat diakses dengan mudah oleh konsumen. Hal tersebut sesuai dengan yang dikemukankan oleh (Akhlaq and Ahmed, 2013) vendor online yang jujur akan memenuhi perjanjian transaksi dengan pelanggan, vendor online yang baik tidak akan sengaja membahayakan pelanggan dan vendor yang kompeten akan melakukan pekerjaan dengan baik mengisi pesanan pelanggan dengan produk yang benar.

Ditegaskan juga dalam penelitian (McKnight and Chervany, 2001) menyoroti trusting beliefs sebagai reaksi kognitif dan afektif yang dihasilkan setelah interaksi trustor dan trustee, dan reaksi ini menentukan sikap saling percaya dan tingkah laku saling percaya. Ketika tingkat kepercayaan konsumen meningkat maka konsumen yakin untuk membeli produk yang mereka inginkan khususnya transaksi dengan metode online. Dengan demikian, konsumen tidak perlu merasa khawatir untuk membeli produk dari luar negeri yang ada di platform Shopee. Karena konsumen dapat melihat langsung kualitas produk dalam foto yang tertera pada aplikasi disertai dengan deskripsi produk yang ditulis penjual dengan jelas dan jujur pada kolom deskripsi produk. Bahkan konsumen dapat berinteraksi langusng dengan penjual luar negeri dengan fasilitas chat yang telah disediakan pada aplikasi Platform. Hal tersebut membantu konsumen lebih dekat dengan para penjual dari luar negeri sehingga meningkatkan kepercayaan terhadap Platform yang menimbulkan niat pembelian pada produk luar negeri. Hal ini mendukung penelitian sebelumnya yang dilakukan oleh (Aldiana, Ramdan, and Samsudin 2018) kekuatan kepercayaan berpengaruh positif dan signifikan terhadap niat beli.

Berdasarkan hasil penelitain ini diketahui bahwa price fairness, dan firm reputation memiliki pengaruh positif dan signifikan terhadap trusting beliefs, sedangkan uncertainty avoidance memiliki pengaruh negatif dan tidak signifikan terhadap trusting beliefs. Hasil dari trusting beliefs memiliki pengaruh positif dan signifikan terhadap purchase intention. Berdasarkan hasil penelitian tersbut, terdapat beberapa implikasi yang dapat diberikan terhadap pihak Platform sebagai marketplace yang menjual produk dari luar negeri.

Variabel Price fairness menggambarkan harga yang dirasa adil sehingga konsumen memiliki niat beli terhadap produk dengan harga yang sesuai dengan keinginan konsumen. Penjual luar 
negeri yang ada di platform menyediakan berbagai macam produk dengan harga yang sangat kompetitif. Jika konsumen ingin mencari salah satu produk pada kolom search di aplikasi maka banyak bermunculan produk serupa dengan harga yang bervariasi. Dalam aplikasi Platform konsumen dapat memfilter harga produk dari harga tertinggi sampai harga terendah, hal ini mempermudah konsumen untuk menentukan harga produk yang diinginkan. Selain itu Platform juga memiliki fitur penawaran harga yang bisa diajukan langsung kepada penjual sehingga konsumen bisa berkomunikasi langsung dengan penjual melalui fitur chat yang disediakan pada aplikasi Platform untuk menentukan kesepakatan mengenai harga produk dengan harga yang dirasa sesuai dan adil. Untuk itu pihak Platform harus mempertahankan hal tersebut. Namun pihak penjual dari luar negeri juga harus cepat dalam merespon penawaran dari konsumen, agar konsumen tidak beralih ke penjual lain. Platform harus lebih banyak mengajak penjual dari luar negeri untuk mengikuti fitur flash sale agar konsumen dapat membeli produk dengan harga yang lebih rendah. Platform juga harus menyesuaikan ongkos kirim produk yang dijual dari luar negeri agar konsumen tetap membeli produk dari toko luar negeri, karena sebagian toko dari luar negeri masih ada yang belum terdaftar promo gratis ongkir dari Platform sehingga hal tersebut menjadi pertimbangan bagi para konsumen. Selain itu penjual dari luar negeri harus memberikan promo menarik lainnya seperti promo beli banyak lebih hemat atau promo bundle.

Variabel Firm Reputation berpengaruh langsung terhadap konsumen dalam meningkatkan kepercayaan pelanggan dan pada akhirnya konsumen memiliki niat beli. Platform memberikan penawaran menarik untuk pembelian produk dari luar negeri, konsumen dapat membeli produk dengan promo gratis ongkir yang ditawarkan oleh Platform sehingga konsumen memiliki keuntungan dan dapat bertransakti dengan aman, hal ini harus dipertahankan oleh pihak Platform, karena dengan adanya produk dari luar negeri memberikan pengalaman yang menarik dalam bertransaksi. Namun karena banyaknya penjual dari luar negeri, konsumen harus lebih cermat lagi dalam memilih produk. Karena masih ada penjual dari luar negeri yang mendapatkan review masih kurang bagus dari konsumen terkait kualitas produk yang tidak sesuai deskripsi gambar, estimasi pengiriman produk yang tidak sesuai, serta pelayanan yang masih lambat dari penjual maupun dari pihak Platform dalam menangani kendala pada transaksi produk dari luar negeri. Untuk itu Platform harus meningkatkan kualitas pelayanan terhadap konsumen yang memiliki kendala dalam bertransaksi produk dari luar negeri, Platform harus menindak lanjut dan menegur penjual luar negeri yang sering memiliki review yang kurang bagus terkait kualitas produk yang dijual jika tidak sesuai dengan deskripsi produk yang dicantumkan.

Trusting Beliefs memiliki pengaruh secara langsung dan sangat berperan penting dalam mempengaruhi niat beli konsumen. Platform harus meningkatkan awereness konsumen terhadap produk yang dijual dari luar negeri, shopee bisa mengajak para penjual luar negeri untuk 
memasarkan produknya dengan fitur Platform live stream agar produknya bisa lebih dikenal luas oleh konsumen millennial. Selain itu shopee harus memberikan informasi yang jelas terkait syarat dan ketentuan dalam proses pengiriman produk. Karakteristik konsumen khususnya millennial semua serba ingin cepat, produk yang dikirim dari luar negeri terbilang cukup lama dalam proses pengirimannya bisa memakan waktu sampai dua minggu sehingga dinilai kurang efisien. Namun ada beberapa toko yang sudah bekerja sama dengan ekspedisi pengiriman cepat yaitu premium ekspres sehingga produk yang dikirim dari luar negeri bisa diterima dalam waktu kurang dari satu minggu. Hal ini harus dipertahankan dan Platform harus lebih banyak mengajak penjual dari luar negeri untuk bekerja sama dengan eskpedisi tersebut sehingga niat beli konsumen bisa terus meningkat. Platform sebagai penengah antara konsumen dan penjual sehingga Platform harus bersikap adil dan tidak memihak terhadap salah satunya. Customer service shopee harus lebih berempati terhadap konsumen yang memiliki kendala agar konsumen merasa keluhannya didengar dan memberikan solusi yang tepat dan cepat dalam menindak lanjuti kendala yang dialami konsumen. Platform juga menjamin produk yang dibeli konsumen aman, dana yang dibayarkan akan di salurkan kepada penjual setelah konsumen menerima produk yang dibeli. Platform dapat memberikan kompensasi pengembalian dana terhadap produk yang memiliki kendala, namun pengembalian dana konsumen prosesnya terbilang lama karena penjual yang bersangkutan dari luar negeri. Sehingga shopee harus menjelaskan dan mengeducate konsumen dengan baik agar konsumen bisa menerima dan mengerti mekanisme proses transaksi produk luar negeri lebih lama.

\section{Kesimpulan}

Berdasarkan analisa dan hasil pemebahasan, dapat peneliti simpulkan sebagai berikut :

Uncertainty Avoidance ternyata memiliki pengaruh negatif dan tidak signifikan terhadap Trusting Belief pada hasil penelitian ini, sementara Price Fairness memiliki pengaruh positif dan signifikan terhadap Trusting Belief pada hasil penelitian ini, dan Firm Reputation memiliki pengaruh positif dan signifikan terhadap Trusting Belief pada hasil penelitian ini, akan tetapi Trusting Belief terbukti memiliki pengaruh positif dan signifikan terhadap Purchase Intention pada hasil penelitian ini.

Dari kesimpulan penelitian ini, terdapat satu variabel eksogen yaitu uncertainty avoidance tidak dapat memberikan pengaruh yang signifikan terhadap trusting beliefs. Oleh karena itu untuk penelitian selanjutnya, peneliti menyarankan untuk memfokuskan dan meneliti lebih dalam pengaruh uncertainty avoidance terhadap trusting beliefs. Dan atau juga dapat menambah variabel lainnya seperti iklan, loyalitas, promosi, attitudes, celebrity endorse sehingga dapat menimbulkan niat melakukan pembelian pada marketplace. 


\section{DAFTAR PUSTAKA}

Akhlaq, A, and E. Ahmed. 2013. "The Effect of Motivation on Trust in the Acceptance of Internet Banking in a Low Income Country." International Journal of Bank Marketing Vol. 31 No: 115-25.

Aldiana, Feny, Asep M. Ramdan, and Acep Samsudin. 2018. "Kekuatan Kepercayaan terhadap Niat Beli Pengunjung Website.” Jurnal Buletin Studi Ekonomi Vol. 23: No. 2.

Becerra.EP, \& Korgaonkar. P, Effects of trust beliefs on consumers' online intentions, European Journal of Marketing, 2011, 45(6):936-962

Brown, T.J., A. D Peter, M.G Pratt, and D.A. Whetten. 2006. "Identity, Intended Image, Contrued Image, and Reputation: An Interdisciplinary Framework and Suggested Terminology." Journal of the academy marketing science. 34(2):99-1.

Campbell, M.C. 1999. "Perceptions of Price Unfairness: Antecedents and Consequences.” Journal of Marketing Research 36 No. 2: 187-99.

Chen, Y. dan S. Barnes. 2007. "Initial Trust and Online Buyer Behaviour". Journal of Industrial Management \& Data Systems, Vol.107, h. 21-36.

Chen, \& Chang. (2012). Enhance green purchase intentions: The roles of green perceived value, green perceived risk, and green trust. Management Decision, 510

Cooper, D. and P. Schindler. 2011. Business Research Methods. Singapore: Mc Graw Hill.

Darsono, I.I. 2008. Hubungan Perceived Service Quality Dan Loyalitas: Peran Trust Dan Satisfaction Sebagai Mediator. The 2nd. Surabaya: National Confrence UKWMS.

DesJardins, J. 2009. An Introduction to Business Ethics. 3rd ed. New York, NY.: McGraw-Hill.

Doney, P.M., and Cannon, J.P. 1997. "An Exaniation of the Nature of Trust in Buyer-Seller Relationship." Journal of Marketing 61: 35-51.

Fombrun, C.J. 1996. Reputation: Realizing Value from the Corporate Image. Boston: Harvard Business School Press.

Ganesan, S. 1994. "Determinants of Long-Term Orientation in Buyer-Seller Relationship." Journal of Marketing Vol. 58 No: 1-19.

Garbarino, E., and O.F. Lee. 2003. "Dynamic Pricing in Internet Retail: Effects on Consumer Trust." Psychology and Marketing Vol. 20 No: 495-513.

Giantari, I.G.A.K., Zain, D., Rahayu, M. \& Solimun, 2013. The role of perceived behavioral control and trust as mediator of experience on online purchasing intentions relationship a study on youths in denpasar city (Indonesia). International Journal of Business and Management Invention, 2(1), pp.30- 38.

Gong, Wen. 2009. "National Culture and Global Diffusion of Business-to-Consumer eCommerce.” Cross Cultural Management: An International Journal 16(1): 83-101. 
Grewal. D, Levy. M, Lehman D., Retail Branding and Customer Loyalty: Journal of Retailing, 2004, An Overview, 80(4) DOI: 10.1016/j.jretai.2004.10.001

Hair, J. F., W. C. Black, B. J. Babin, and R. E. Anderson. 2010. Multivariate Data Analysis. 7th ed. USA: New Jersey: Pearson.

Herrmann, Andreas, Lan Xia, Monroe B. Kent, and Frank Huber. 2007. "The Influence of Price Fairness on Customer Satisfaction: An Empirical Test in the Context of Automobile Purchases." Journal of Product and Brand Management 16(1): 49-58.

Hess, Ronald L. 2008. "The Impact of Firm Reputation and Failure Severity on Customers' Responses to Service Failures." Journal of Services Marketing 22(5): 385-98.

Hofstede, G. 2001. Culture's Consequences: Comparing Values, Behaviours, Institutions, and Organizations Across Nations,. 2nd ed.,. Sage,: Thousand Oaks, CA.

Hofstede, G. 2004. "Business Goals and Corporate Governance." Asia Pacific Business Review Vol. 10 No: 292-301.

Hwang, Y. 2009. "The Impact of Uncertainty Avoidance, Social Norms, and Innovativeness on Trust and Ease of Use in Electronic Customer Relationship Management." Journal of Electronic Market Vol. 19 No: 89-98.

Hwang, Y., and K. C. Lee. 2012. "Investigating the Moderating Role of Uncertainty Avoidance Cultural Values on Multidimensional Online Trust." Information \& Management, 49 (3): 171176.

Hsu C, Shen YC, Cheng CC, Hu FC, Cheng AL. Geographic difference in survival outcome for advanced hepatocellular carcinoma: implications on future clinical trial design. Contemp Clin Trials. 2010;31:55-61

Johnson, D., \& Grayson, K. (2005). Cognitive and affective trust in service relationships. Journal of Business Research, 58(4), 500-507. https://doi.org/10.1016/S0148-2963(03)00140-1.

Kailani.M.A, Kumar R, Investigating Uncertainty Avoidance and Perceived Risk for Impacting Internet Buying: A Study in Three National Cultures, International Journal of Business and Management, 2011, May, Vol. 6, No. 5;

Kalapurakal, R., P. R. Dikson and 1. E. Urbany (1991), Perceived Price Fairness and Dual Entitlement," in Advances in Consumer Research, Vol. XVIII: Association for Consumer Research.

Kim, H.-W., Y. Xu, and S. Gupta. 2012. "Which Is More Important in Internet Shopping, Perceived Price or Trust?” Electronic Commerce Research and Applications Vol. 11 No: 241-252.

Kinnear, Thomas C, and James R Taylor. 2003. Riset Pemasaran (Terjemahan Oleh Thamrin). Edisi Tiga. Jakarta: Erlangga.

Kotler, P., Bowen, J. T., and J. C. Makens. 2014. Marketing for Hospitality and Tourism. 5 theditio. New Jersey: Pearson Prentice Hall. 
Kotler, Philip, and Kevin Lane Keller. 2012. Principle Of Marketing. 14th editi. New Jersey: Prentice.

Koufaris, M. and Hampton-Sosa, W. (2004), "The development of initial trust in an online company by new customers", Information and Technology, Vol. 41 No. 3, pp. 377-397.

Lee, Julie Anne, Ellen Garbarino, and Dawn Lerman. 2007. "How Cultural Differences in Uncertainty Avoidance Affect Product Perceptions." International Marketing Review 24(3): 330-49.

Lupiyoadi (2001) Manajemen Pemasaran Jasa Teori dan Praktek, Salemba Empat, Jakarta

Malhotra, N.K. 2010. Marketing Research : An Applied Orientation. Prentice Hall: Upper Saddle Pearson.

Malhotra, Naresh K., and David F. Birks. 2012. Marketing Research: An Applied Approach 3rd European Edition. Harlow, England: Prentice-Hall.

Mayer, R.C., J.H Davis, and F.D Schoorman. 1995. "An Integrative Model of Organisational Trust." Academy of Management Review 20 No. 3: 709-34.

McKnight, D.H., and N.L. Chervany. 2001. "What Trust Means in E-Commerce Customer Relationships: An Interdisciplinary Conceptual Typology." International Journal of Electronic Commerce 6 No. 2: 35-59.

McKnight, D.H., V. Choudhury, and C. Kacmar. 2002. "Developing and Validating Trust Measures for E-Commerce: An Integrative Topology." Journal of Information Systems Research Vol. 13 No: 334-359.

Mcknight, D Harrison, Larry L Cummings, and Norman L Chervany. 1998. "InitialTrustAMR." Academy of management review 23(3): 473-90.

Mowen, John C., and M. Minor. 2002. Perilaku Konsumen. Jakarta: Erlangga.

P, Elvani Marcelin, Marvin Anggasta, M Fandhi Al-barru, and Prisa Ngadianto. 2016. "Sikap Pelanggan Millennial Indonesia Terhadap Iklan Online.” : 1-19.

Pan, L.-Y., and J.-S. Chiou. 2011. "How Much Can You Trust Online Information? Cues for Perceived Trustworthiness of Consumer-Generated Online Information"." Journal of Interactive Marketing Vol. 25 No: 67-74.

Ring, P.S. and Van de Ven, A.M. (1994), "Development process of cooperative interorganisational relationships", Academy of Management Review, Vol. 19 No. 1, pp. 90-118.

Rose, S., Clark, M., Samouel, P. and Hair, N. (2012), "Online customer experience in e-retailing: an empirical model of antecedents and outcomes", Journal of Retailing, Vol. 88 No. 2, pp. 308-322.

Sahi, Gurjeet Kaur, Harjit Singh Sekhon, and Tahira Khanam Quareshi. 2016. "Role of Trusting Beliefs in Predicting Purchase Intentions." International Journal of Retail and Distribution Management 44(8): 860-80. 
Salo. J, and Karjaluoto. H, A conceptual model of trust in the online environment, Online Information Review, 2007, Vol. 31 No. 5, pp. 604-621q, Emerald Group Publishing Limited1468-4527

Santoso, S. 2012. Analisis SEM Menggunakan AMOS. Jakarta: PT. Elex Media Komputindo.

Sekhon, H., C. Ennew, H. Kharouf, and J. Devlin. 2014. "Trustworthiness and Trust: Influences and Implications." Journal of Marketing Management 30 Nos 3/4: 409-30.

Simamora, Bilson. 2002. Panduan Riset Perilaku Konsumen. Surabaya: Pustaka Utama.

Schiffman, Leon G., Leslie Lazar Kanuk. 2007. Consumer Behavior, Ninth Edition. New Jersey: Pearson Education International.

Shobeiri, S., Mazaheri, E. and Laroche, M. (2014), "Improving customer website involvement through experiential marketing", The Service Industries Journal, Vol. 34 No. 11, pp. 885-900.

Tjiptono, Fandy. 2008. Strategi Bisnis Pemasaran. Yogyakarta: Andi.

Vance, A., C. Elie-Dit-Cosaque, and D. Straub. 2008. "Understanding Trust in It Artefacts: The Effects of Service Quality and Culture on Trust." Journal of Management Information Systems Vol. 24 No: 73-100.

Walsh, Vincent-Wayne Mitchell, Paul R. Jackson, and Sharon E. Betty. 2008. "Examining the Antecendents and Consequences of Corporate Reputation: A Customer Perspective." British Journal of Management Vol.8:1-7.

White, T.B., and H. Yuan. 2011. "Building Trust to Increase Purchase Intentions: The Signaling Impact of Low Pricing Policies.” Journal of Consumer Psychology Vol. 20 No: 384-94.

Wijanto, S. H. 2008. Structural Equation Modeling. GrahaIlmu.

Marshal, Brian. 2020. https://www.cnnindonesia.com/teknologi/20200205204206-206472064/tren-dan-peluang-industri-e-commerce-di-indonesia-2020, Kamis, 06 Februari 2020.

Pranata, Nika. Lembaga Penelitian Indonesia (LIPI), 2019, https://bisnis.tempo.co/read/1283370/survei-lipi-ungkap-2-alasan-warga-ri-belanjaonline-produk-impor, Jumat ,13 Desember 2019.

Soemartono, Henri. K. 2018. http://marketeers.com/143-juta-internet-user-di-indonesia565662/. 21 February 2018 